\title{
Pemetrexed for previously treated patients with metastatic gastric cancer: a prospective phase II study
}

\author{
D S Zhang ${ }^{1,2}, Y$ Jin $^{1,2}, \mathrm{H}$ Y Luo ${ }^{1}, \mathrm{Z}$ Q Wang ${ }^{1}, \mathrm{M} \mathrm{Z} \mathrm{Qiu^{1 } , \mathrm { F } \mathrm { H } \mathrm { Wang }}{ }^{1}, \mathrm{Y} \mathrm{H} \mathrm{Li}{ }^{1}$ and R H X ${ }^{*, 1}$ \\ ${ }^{1}$ Department of Medical Oncology, Sun Yat-sen University Cancer Center, State Key Laboratory of Oncology in South China, \\ Collaborative Innovation Center for Cancer Medicine, Guangzhou 510060, China
}

Background: Gastric cancer is one of the leading causes of cancer-related death worldwide. There were debates on the value of the second-line and beyond chemotherapy by the time we designed this trial. So we designed this phase II trial to assess the efficacy and safety of pemetrexed in patients with pretreated metastatic gastric cancer.

Methods: Thirty-four patients with pretreated metastatic gastric cancer were enroled in the study. Patients received pemetrexed $500 \mathrm{mg} \mathrm{m}^{-2}$ every 21 days until the presence of progressive disease (PD) or unacceptable toxicity.

Results: A total of 34 patients were enroled in the study; 34 were eligible for toxicity and 30 for response. The response rate was 13.3\%, 13.3\% patients achieved a partial response, 50.0\% achieved stable disease and 36.7\% had a PD as the best response. The median overall survival time and median progression-free survival time was 6.4 months (95\% confidence interval (Cl) $5.8-9.5$ months) and 2.2 months (95\% Cl 2.0-5.5 months), respectively. Most haematologic and non-haematologic toxicity were grade 1/2. Grade 3/4 toxicity included fatigue, neutropenia, thrombocytopenia, weight loss, anorexia and transaminase elevation.

Conclusions: The monochemotherapy of pemetrexed is active and well tolerated when used in previously treated patients with metastatic gastric cancer.

Gastric cancer is the second leading cause of cancer-related death worldwide, with hundreds of thousands of newly diagnosed cases each year (Jemal et al, 2011). Although surgical resection is the only curative treatment, many patients with metastatic disease have lost the opportunity to receive surgery due to late diagnosis (Wang et al, 2010). For such patients, palliative chemotherapy is the mainstay treatment to prolong their survival. Systemic chemotherapy based on 5-fluoropyrimide (5-FU)/platinum plus human epidermal growth factor receptor-2 antibody or not has proved to be effective first-line therapy (Demolin et al, 2008; Bang et al, 2010). But the response rate of first-line therapy is limited and the duration of responses was only a few months, which means that many patients who retain a good performance after previous chemotherapy remain good candidates for further treatment.
When designing this trial, there were debates on the value of the second-line and beyond chemotherapy. Some physicians considered that administration of salvage chemotherapy will only add to patients suffering without prolonging their life. Some argued that improvements in the overall survival (OS) as well as the quality of life could be found in the patients who received an active and tolerable chemotherapy after carefully selecting (Park et al, 2006; Ji et al, 2009; Wesolowski et al, 2009). Although survival benefits were seen in some phase II trials with different chemotherapy regimens, there was no standard regimen for pretreated metastatic gastric cancer.

Pemetrexed is a pyrrolopyrimidine antifolate that has established its promising efficacy in the treatment of patients with advanced mesotholioma and non-small cell lung cancer. It is

\footnotetext{
*Correspondence: Professor RH Xu; E-mail:xurh@sysucc.org.cn

${ }^{2}$ These authors contributed equally to this work.
}

Received 12 July 2014; revised 12 October 2014; accepted 6 November 2014; published online 4 December 2014 
referred to as a multitargeted antifolate because it inhibits at least three folate-dependent enzymes, including thymidylate synthase, dihydrofolate reductase and glycinamide ribonucleotide formyl transferase (Shih et al, 1998). The clinical activity has also been seen in some clinical trials for treatment of bladder, breast, colon, pancreas and gastric cancer (Kut et al, 2004). Previous phase II trials have shown that, when used either as a single agent or in combination as first-line chemotherapy, pemetrexed is an acceptable safety profile in metastatic gastric cancer, with beneficial activity (RR 21-36\%; median OS 6.6-11.8 months; median progression-free survival (PFS) 2.8-6.2 months; Bajetta et al, 2003; Kim et al, 2008; Celio et al, 2009; Chen et al, 2010). As we know, there are few clinical trials that reported the activity and tolerability of pemetrexed as salvage monochemotherapy in metastatic gastric cancer.

The aim of this phase II study is to evaluate the efficacy and safety of single-agent pemetrexed in previously treated patients with metastatic gastric cancer.

\section{PATIENTS AND METHODS}

Patients. Eligible criteria included histologically confirmed inoperable or metastatic adenocarcinoma of the stomach or gastrooesophageal junction, at least one prior chemotherapy regimen, measurable disease by Response Evaluation Criteria in Solid Tumors (RECIST), age between 18 and 80 years, ECOG performance status of $0-2$ and life expectancy $\geqslant 12$ weeks. Exclusion criteria included other primary malignancy, symptomatic central nervous system metastasis, pregnancy or lactation, cardiovascular events in the previous 6 months or congestive heart failure, ongoing infection, inability or unwillingness to take nonsteroidal anti-inflammatory drugs or folic acid or vitamin B12 supplementation.

Patients and disease evaluations. Baseline examination, performed within 3 weeks of commencing treatment, included a complete history and physical examination, complete blood count, blood chemistries, urinalysis, electrocardiogram, tumour markers and a computed tomography (CT) scan of chest, abdomen and pelvis. One study's evaluations (every 21 days) included a limited history and physical examination, complete blood count and blood chemistries, performance status evaluation and toxicity rating. Toxicity evaluations were based on the Common Terminology Criteria for Adverse Event (CTCAE) Version 3.0. Disease assessment by CT scan was performed every two cycles of therapy to ensure that patients with other treatment options were not rapidly progressing. Response to treatment was assessed by means of CT scan using RECIST guidelines (version 1.1) every two cycles of treatment.

Study medications. Patients received pemetrexed $500 \mathrm{mg} \mathrm{m}^{-2}$, once every 21 days, until the presence of progressive disease (PD) or unacceptable toxicity. All patients took dexamethasone $3.75 \mathrm{mg}$ twice daily, starting from the day before and continuing to the day after the drug administration. Patients were instructed to take oral folic acid $400 \mathrm{mg}$ daily beginning 5 days before the first therapy and until the final therapy. Treatments would continue until unacceptable toxicity or disease progression occurred. In addition, dose adjustment was based on the toxicity of the preceding administration of pemetrexed. If a patient developed grade 4 neutropenia, grade 3 febrile neutropenia or grade 3 thrombopenia, drug dosage was reduced by $25 \%$ in the subsequent treatment cycles. If a patient developed grade 4 febrile neutropenia or grade 4 thrombopenia, drug dosage was reduced by $50 \%$ in the subsequent treatment cycles. If a patient develops a grade 3-4 mucositis, pharyngitis, oesophagitis or diarrhoea during treatment, drug dosage was reduced by $25 \%$ in the subsequent treatment cycles only after the toxicity had been resolved to less than grade 2. If drug administration was delayed for more than 4 weeks, the patient was excluded from the study. Treatment would not be interrupted when a patient had a toxicity that had no clinical influence.

Study design and statistical analysis. This is a phase II, nonrandomized, open-label trial. The primary end point of this study was ORR. A Simon's two-stage design was utilised to calculate sample size with $p_{0}=0.05$ (null hypothesis) and $p_{1}=0.25$ (alterative hypothesis), with a significance level of 0.05 and a power of $90 \%$ (Simon, 1989). A sample size of 9 is needed for the first stage, and if at least 1 of these patients achieved objective response, further 21 patients were to be recruited in the second stage. The rate of loss to follow-up was expected to be $<15 \%$. Therefore, the sample size was increased to 10 in the first stage and 24 in the second stage for a total sample size of 34 patients. ORR was evaluated in patients who received at least one dose of pemetrexed and underwent at least one post-baseline assessment. Patients who received at least one cycle of treatment were included in the safety analysis. The regimen was considered to be active if four or more patients had an objective response. The secondary end points of this study included OS, PFS, DCR and the toxicity profile. OS was measured from the date of consent to the time of death, and PFS from the date of consent to the first observation of PD. All patients were to be followed until death or 30 April 2014. OS and PFS were analysed using the Kaplan-Meier method. Exact 95\% confidence interval (CI) was estimated for the variables. The analyses were performed using SPSS (Statistical Package for the Social Sciences) 16.0 software for the Windows operating system (SPSS Inc, Chicago, IL, USA).

The study was approved by the Ethical Review Board of Sun Yat-sen University Cancer Center, and followed the ethical principles of Good Clinical Practice in accordance with the Declaration of Helsinki. All patients signed a written informed consent document before enrolment. The clinical trial was registered with clinicaltrials.gov (identifier NCT01953419).

\section{RESULTS}

Patient characteristics. From October 2010 to December 2013, a total of 34 patients were enroled in the study. Baseline patient characteristics are summarised in Table 1 . Majority of the patients are male $(58.8 \%)$, with a median age of 49 years (range $27-80$ ). In total, $7(20.6 \%)$ of the patients had an ECOG performance status of $0,20(58.8 \%)$ had an ECOG performance status of 1 and the rest 7 (20.6\%) had an ECOG performance status of 2 . Of the 34 patients, $25(73.5 \%)$ received pemetrexed as second-line treatment and 9 $(26.5 \%)$ as third- or fourth-line treatment. Six patients had prior curative gastric resection and 11 received prior palliative surgery. Most frequent metastatic sites are lymph node (55.9\%), peritoneum $(47.1 \%)$ and liver $(38.2 \%)$.

Treatment summary. Among the 34 patients enroled, 30 patients were assessable. Two patients who had an ECOG performance status of 2 had deterioration in their physical condition not considered to be related to the chemotherapy and stopped chemotherapy without a CT reassessment. One patient refused to take a CT assessment after treatment. One patient with multiple peritoneal metastases turned to receive best supportive care due to severe hypoproteinaemia. This left 30 patients in the primary analysis and 34 patients in the toxicity analysis. The patients enroled in this study received a median of three cycles of pemetrexed, ranged from 1 to 6 . Of the 30 patients qualified for efficacy analysis, only 1 patient required a dose reduction because of intolerable toxicity.

Efficacy. The details of treatment efficacy are shown in Table 2. Four of 30 assessable patients $(13.3 \%)$ achieved a partial response 
Table 1. Patient characteristics $(n=34)$

\begin{tabular}{|c|c|}
\hline Patient characteristics & $n(\%)$ \\
\hline \multicolumn{2}{|l|}{ Age, years } \\
\hline $\begin{array}{l}\text { Median } \\
\text { Range }\end{array}$ & $\begin{array}{c}49 \\
27-80\end{array}$ \\
\hline \multicolumn{2}{|l|}{ Gender } \\
\hline $\begin{array}{l}\text { Male } \\
\text { Female }\end{array}$ & $\begin{array}{l}20(58.8) \\
14(41.2)\end{array}$ \\
\hline \multicolumn{2}{|l|}{ ECOG } \\
\hline $\begin{array}{l}0 \\
1 \\
2\end{array}$ & $\begin{array}{r}7(20.6) \\
20(58.8) \\
7(20.6)\end{array}$ \\
\hline \multicolumn{2}{|c|}{ Number of prior regimens } \\
\hline $\begin{array}{l}1 \\
\geqslant 2\end{array}$ & $\begin{array}{r}25(73.5) \\
9(26.5)\end{array}$ \\
\hline \multicolumn{2}{|l|}{ Prior surgery } \\
\hline $\begin{array}{l}\text { None } \\
\text { Curative } \\
\text { Palliative }\end{array}$ & $\begin{array}{r}17(50.0) \\
6(17.6) \\
11(32.4)\end{array}$ \\
\hline \multicolumn{2}{|c|}{ Number of organ involved } \\
\hline $\begin{array}{l}1 \\
2 \\
\geqslant 3\end{array}$ & $\begin{array}{r}8(23.5) \\
16(47.1) \\
10(29.4)\end{array}$ \\
\hline \multicolumn{2}{|l|}{ Disease sites } \\
\hline $\begin{array}{l}\text { Lymph node } \\
\text { Peritoneum } \\
\text { Liver } \\
\text { Lung } \\
\text { Bone } \\
\text { Others }\end{array}$ & $\begin{array}{l}19(55.9) \\
16(47.1) \\
13(38.2) \\
6(17.6) \\
4(11.7) \\
3(8.8)\end{array}$ \\
\hline
\end{tabular}

(PR), 15 patients (50\%) achieved stable disease (SD) and 11 patients (36.7\%) had a PD as the best response (ORR 13.3\%; DCR 63.3\%). Among 22 patients who received pemetrexed as a secondline chemotherapy, 4 patients (18.2\%) achieved PR, 10 patients (45.4\%) achieved SD and the rest had a PD (ORR 18.2\%; DCR $63.6 \%)$. Among eight patients who previously received two or more lines of chemotherapy, five patients $(62.5 \%)$ achieved SD and the rest had a PD (ORR 0.0\%; DCR 62.5\%). Of the 30 assessable patients who received pemetrexed, 2 were alive at the last followup; the median OS was 6.4 months (95\% CI 5.8-9.5 months) and 6.4 months (95\% CI 5.2-10.0 months) for the second-line group and 6.0 months (95\% CI 4.5-11.2 months) for the third-line and beyond group; the median PFS was 2.2 months (95\% CI $2.0-5.5$ months) and 2.3 months (95\% CI 1.9-6.5 months) for the secondline group and 2.2 months (95\% CI 1.3-4.1 months) for the thirdline and beyond group.

Safety. All 34 patients who were enroled in the study were evaluated for toxicity. The toxicities were summarised in Table 3. There was no treatment-related mortality. Totally, 27 (79.4\%) patients had at least one adverse event, most commonly anaemia, anorexia and nausea. Most haematologic and non-haematologic toxicities were grade 1 or 2 . Grade 3 or 4 toxicity included fatigue, neutropenia, thrombocytopenia, weight loss, anorexia and transaminase elevation. Three patients discontinued the treatment because of worse performance status or severe hypoproteinaemia after the first cycle. No one delayed the treatment, but one patient required a dose reduction due to grade 4 thrombopenia.

\section{DISCUSSION}

The result of this study demonstrated that pemetrexed is a rational option for salvage treatment, especially for second-line
Table 2. Treatment response of all assessable patients and by previous treatment group

\begin{tabular}{|c|c|c|c|}
\hline & $\begin{array}{c}\text { All } \\
\text { patients } \\
(n=30)\end{array}$ & $\begin{array}{c}\text { Second-line } \\
\text { group }(n=22)\end{array}$ & $\begin{array}{l}\text { Third-line and } \\
\text { beyond group } \\
(n=8)\end{array}$ \\
\hline \multicolumn{4}{|l|}{ Response } \\
\hline PR & $4(13.3 \%)$ & $4(18.2 \%)$ & 0 (0.0\%) \\
\hline SD & 15 (50.0\%) & 10 (45.4\%) & 5 (62.5\%) \\
\hline PD & 11 (36.7\%) & 8 (36.4\%) & $3(37.5 \%)$ \\
\hline ORR $(95 \% \mathrm{Cl})$ & $13.3 \%$ & $18.2 \%$ & $0.0 \%$ \\
\hline DCR $(95 \% \mathrm{Cl})$ & $63.3 \%$ & $63.6 \%$ & $62.5 \%$ \\
\hline
\end{tabular}

Table 3. Toxicity of the patients enroled in the study (worst grade per patients; $n=34$ )

\begin{tabular}{|l|c|c|c|l|}
\hline Adverse Event & $\begin{array}{c}\text { All } \\
\text { grades(no.) }\end{array}$ & \multicolumn{1}{|c|}{$\begin{array}{c}\text { Grade 3 } \\
\text { or 4(no.) }\end{array}$} & \% \\
\hline Any AEs & 27 & 79.4 & & \\
\hline Haematologic AEs & \multicolumn{5}{|l|}{} \\
\hline Neutropenia & 8 & 23.5 & 1 & 2.9 \\
Leukopenia & 9 & 26.5 & 0 & 0 \\
Anaemia & 19 & 55.9 & 1 & 2.9 \\
Thrombocytopenia & 4 & 11.8 & 1 & 2.9 \\
\hline Non-haematologic AEs & \multicolumn{5}{|l}{} \\
\hline Nausea & 10 & 29.4 & 0 & 0 \\
Anorexia & 13 & 38.2 & 1 & 2.9 \\
Vomiting & 4 & 11.8 & 0 & 0 \\
Diarrhoea & 1 & 2.9 & 0 & 0 \\
Constipation & 2 & 5.8 & 0 & 0 \\
Fatigue & 9 & 26.5 & 2 & 5.8 \\
Weight loss & 7 & 20.6 & 1 & 2.9 \\
Bilirubin & 5 & 14.7 & 0 & 0 \\
Transaminases & 11 & 32.4 & 1 & 2.9 \\
Neutropathy & 1 & 2.9 & 0 & 0 \\
Alopecia & 1 & 2.9 & 0 & 0 \\
Rash & 2 & 5.8 & 0 & 0 \\
\hline
\end{tabular}

chemotherapy, when administered at a dose of $500 \mathrm{mg} \mathrm{m}^{-2}$ every 21 days to patients with metastatic gastric cancer. In this study, pemetrexed produced an ORR of $13.3 \%$ and DCR of $63.3 \%$ and the chemotherapy was well tolerated that there were no deaths resulted from toxicity.

During the progress of our study, results from several phase 3 randomized clinical trials were reported, supported that savage chemotherapy could add to patients' survival benefits (Thuss-Patience et al, 2011; Kang et al, 2012). A survival advantage was seen from the German Arbeitsgemeinschaft Internistische Onkologie (AIO) trial for irinotecan vs best supportive care, with an increased OS of 1.6 months. However, the trial was closed prematurely after accrual of only 40 patients over the first 4 years. The median survival time of the treatment group was only 4.0 months, and irinotecan produced no objective responses and SD in 53\% (Thuss-Patience et al, 2011). Another phase 3 trial of 193 patients compared BSC combined with either docetaxel or irinotecan with BSC alone, reporting an OS improvement of 1.3 months (Kang et al, 2012). A recently published phase 3 randomized controlled trial, COUGAR-02 trial, suggested that docetaxel can be recommended as an appropriate second-line treatment for patients with oesophagogastric adenocarcinoma (Ford et al, 2014). Furthermore, the median OS in the docetaxel group was 5.2 months vs 3.6 months in the active symptom control group. Biological agents have also had an important role in secondline treatment of gastric cancer. The result of REGARD study suggested that ramucirumab, a monoclonal antibody VEGFR-2 
antagonist, could significantly increase OS from 3.8 months to 5.2 months for patients with previously treated advanced gastric cancer, compared with the placebo (Fuchs et al, 2014). The RAINBOW study showed that the combination of ramucirumab with paclitaxel significantly increases OS compared with placebo plus paclitaxel (Wilke et al, 2014). Overall survival was significantly longer in the ramucirumab plus paclitaxel group than in the placebo plus paclitaxel group (median 9.6 months $v s$ 7.4 months).

Although second-line chemotherapy is active for advanced gastric cancer, the standard treatment strategy is still debating. WJOG4007 trial, a randomized phase 3 head-to-head trial, designed to compare two second-line regimens CPT-11 and wPTX for AGC, did not demonstrate the superiority one, indicating that the different choices of chemotherapy seem not to impact on the outcome. Moreover, the patients involved in the clinical trials were in good physical condition, whereas in clinical practice there were patients with poor status due to disease progression and previous treatment. For instance, for patients with ascites, oedema, intestinal obstruction or poor bone marrow function, taxanes or iritecan, which was associated with higher incidence of grade 3-4 neutropenia or diarrhoea, might not be a good choice because of the toxicity. Recently, multiple new drugs including S-1, oxaliplatin and pemetrexed have proved to be effective and tolerated in gastric cancer (Suh et al, 2005; Barone et al, 2007; Ishigami et al, 2008; Chon et al, 2011). Therefore, more treatment choices of effective salvage regimens with acceptable toxicity for previously treated metastatic gastric cancer are deserved exploring.

For pretreated patients with metastatic gastric cancer, monochemotherapy may be a reasonable choice as second-line treatment, as patients may have worse condition and lower tolerability of further chemotherapy. For such patients, response rate is not most important as in first-line treatment. Chemotherapy with less toxicity, better disease control and life prolongation should be considered preferentially. Some phase II trials showed that combination chemotherapy achieved no marked survival benefits in the second-line setting (Takiuchi, 2011; Kang et al, 2012). Therefore, we chose not combination but single agent for the second-line treatment. For similar reasons, we set the dosage of $500 \mathrm{mg} \mathrm{m}^{-2}$ for pemetrexed, referenced from previous studies in which pemetrexed achieved a modest activity with acceptable toxicity (Hanauske et al, 2001; Bajetta et al, 2003).

As the patients enroled in our study were treated with one or more prior chemotherapy, the activity of pemetrexed may be modest compared with that in previous pemetrexed trials in first-line setting. But when compared with other secondline chemotherapy regimens, pemetrexed achieved a comparable activity. The common second-line regimens, commonly based on taxanes, iritecan, platinum and 5-FU, administered in combination or as single agent, produced a median OS of about 5-13 months, median PFS of about 2-4 months and ORR of about 5-30\% (Wesolowski et al, 2009; Baek et al, 2012). Despite the difference in regimens, the activity might also be influenced by some potential prognostic factors, including time to progression on first-line treatment, serum albumin, performance status and chemotherapy-free interval. Considering that one-third patients enroled in the study were pretreated with two or more chemotherapy, our study showed that pemtrexed produced a considerable efficacy, with a median OS of 6.4 months, median PFS of 2.2 months and ORR of $13.3 \%$ in all patients and a median OS of 6.4 months, median PFS of 2.3 months and ORR of $18.2 \%$ in second-line group.

In summary, the preliminary activity and manageable toxicity observed in this study suggest that pemetrexed $\left(500 \mathrm{mg} \mathrm{m}^{-2}\right)$ has a therapeutic role in salvage treatment of metastatic gastric cancer. Further investigations are needed to compare pemetrexed with other agents in salvage treatment of gastric cancer.

\section{ACKNOWLEDGEMENTS}

This work was supported by grants from National High Technology Research and Development Program of China (863 Program), No. 2012AA02A506; Natural Science Foundation of China, No. 81372570; National Natural Science Foundation of China, No. 81372570; The Science and Technology Department of Guangdong Province, China, No. 2012B031800088; Medical Scientific Research Foundation of Guangdong Province, China, No. C2011019; and Qilu pharmaceutical Co., LTD. The funders had no role in study design, data collection and analysis, decision to publish or preparation of the manuscript.

\section{CONFLICT OF INTEREST}

The authors declare no conflict of interest.

\section{REFERENCES}

Baek SK, Kim SY, Jeong JH, Cho KS, Yoon HJ (2012) Second-line chemotherapy for advanced gastric cancer in Korea. Gastric Cancer 15 345-354.

Bajetta E, Celio L, Buzzoni R, Ferrari L, Marchiano A, Martinetti A, Longarini R, Becerra C, Ilardi C, John W (2003) Phase II study of pemetrexed disodium (Alimta) administered with oral folic acid in patients with advanced gastric cancer. Ann Oncol 14: 1543-1548.

Bang YJ, van Cutsem E, Feyereislova A, Chung HC, Shen L, Sawaki A, Lordick F, Ohtsu A, Omuro Y, Satoh T, Aprile G, Kulikov E, Hill J, Lehle M, Ruschoff J, Kang YK (2010) Trastuzumab in combination with chemotherapy versus chemotherapy alone for treatment of HER2-positive advanced gastric or gastro-oesophageal junction cancer (ToGA): a phase 3, open-label, randomised controlled trial. Lancet 376: 687-697.

Barone C, Basso M, Schinzari G, Pozzo C, Trigila N, D’Argento E, Quirino M, Astone A, Cassano A (2007) Docetaxel and oxaliplatin combination in second-line treatment of patients with advanced gastric cancer. Gastric Cancer 10: 104-111.

Celio L, Sternberg CN, Labianca R, La Torre I, Amoroso V, Barone C, Pinotti G, Cascinu S, Di Costanzo F, Cetto GL, Bajetta E (2009) Pemetrexed in combination with oxaliplatin as a first-line therapy for advanced gastric cancer: a multi-institutional phase II study. Ann Oncol 20: 1062-1067.

Chen JS, Chao Y, Bang YJ, Roca E, Chung HC, Palazzo F, Kim YH, Myrand SP, Mullaney BP, Shen LJ, Linn C (2010) A phase I/II and pharmacogenomic study of pemetrexed and cisplatin in patients with unresectable, advanced gastric carcinoma. Anticancer Drugs 21: $777-784$.

Chon HJ, Rha SY, Park HS, Shin SJ, Kim HS, Roh JK, Noh SH, Chung HC, Jeung HC (2011) Salvage chemotherapy of biweekly irinotecan plus S-1 (biweekly IRIS) in previously treated patients with advanced gastric cancer. Cancer Chemother Pharmacol 68: 991-999.

Demolin G, Focan C, Plomteux O, Kreutz F, Moeneclaey N, Focan-Henrard D (2008) [Chemotherapy for human gastric cancer: a review]. Rev Med Liege 63: $532-541$.

Ford HE, Marshall A, Bridgewater JA, Janowitz T, Coxon FY, Wadsley J, Mansoor W, Fyfe D, Madhusudan S, Middleton GW, Swinson D, Falk S, Chau I, Cunningham D, Kareclas P, Cook N, Blazeby JM, Dunn JA and Investigators C (2014) Docetaxel versus active symptom control for refractory oesophagogastric adenocarcinoma (COUGAR-02): an open-label, phase 3 randomised controlled trial. Lancet Oncol 15: $78-86$.

Fuchs CS, Tomasek J, Yong CJ, Dumitru F, Passalacqua R, Goswami C, Safran H, Dos Santos LV, Aprile G, Ferry DR, Melichar B, Tehfe M, Topuzov E, Zalcberg JR, Chau I, Campbell W, Sivanandan C, Pikiel J, Koshiji M, Hsu Y, Liepa AM, Gao L, Schwartz JD, Tabernero J and Investigators RT (2014) Ramucirumab monotherapy for previously treated advanced gastric or gastro-oesophageal junction adenocarcinoma (REGARD): an international, randomised, multicentre, placebocontrolled, phase 3 trial. Lancet 383: 31-39. 
Hanauske AR, Chen V, Paoletti P, Niyikiza C (2001) Pemetrexed disodium: a novel antifolate clinically active against multiple solid tumors. Oncologist 6: $363-373$.

Ishigami S, Natsugoe S, Nakajo A, Matsumoto M, Uenosono Y, Arigami T, Setoyama T, Arima H, Uchikado Y, Kita Y, Sasaki K, Aikou T (2008) Salvage gastrectomy following a combination of biweekly paclitaxel and S-1 for stage IV gastric cancer. J Gastrointest Surg 12: 1370-1375.

Jemal A, Bray F, Center MM, Ferlay J, Ward E, Forman D (2011) Global cancer statistics. CA Cancer J Clin 61: 69-90.

Ji SH, Lim do H, Yi SY, Kim HS, Jun HJ, Kim KH, Chang MH, Park MJ, Uhm JE, Lee J, Park SH, Park JO, Park YS, Lim HY, Kang WK (2009) A retrospective analysis of second-line chemotherapy in patients with advanced gastric cancer. BMC Cancer 9: 110.

Kang JH, Lee SI, Lim do H, Park KW, Oh SY, Kwon HC, Hwang IG, Lee SC, Nam E, Shin DB, Lee J, Park JO, Park YS, Lim HY, Kang WK, Park SH (2012) Salvage chemotherapy for pretreated gastric cancer: a randomized phase III trial comparing chemotherapy plus best supportive care with best supportive care alone. J Clin Oncol 30: 1513-1518.

Kim YH, Chung HC, Kang WK, Park SR, Kim CS, Kim TY, Shin SW, Park BJ, Cha SJ, Bang YJ (2008) Pemetrexed and cisplatin in patients with advanced gastric cancer: a Korean cancer study group multicenter phase II study. Cancer Chemother Pharmacol 62: 263-270.

Kut V, Patel JD, Argiris A (2004) Pemetrexed: a novel antifolate agent enters clinical practice. Expert Rev Anticancer Ther 4: 511-522.

Park SH, lee WK, Chung M, Bang SM, Cho EK, Lee JH, Shin DB (2006) Quality of life in patients with advanced gastric cancer treated with second-line chemotherapy. Cancer Chemother Pharmacol 57: 289-294.

Shih C, Habeck LL, Mendelsohn LG, Chen VJ, Schultz RM (1998) Multiple folate enzyme inhibition: mechanism of a novel pyrrolopyrimidine-based antifolate LY231514 (MTA). Adv Enzyme Regul 38: 135-152.

Simon R (1989) Optimal two-stage designs for phase II clinical trials. Control Clin Trials 10: 1-10.
Suh SH, Kwon HC, Jo JH, Cho YR, Seo BG, Lee DM, Kim SH, Kim JS, Kim HJ (2005) Oxaliplatin with biweekly low dose leucovorin and bolus and continuous infusion of 5-fluorouracil (modified FOLFOX 4) as a salvage therapy for patients with advanced gastric cancer. Cancer Res Treat 37: 279-283.

Takiuchi H (2011) Second-line chemotherapy for gastric cancer: a new issue lies ahead in global trials. Gastric Cancer 14: 206-211.

Thuss-Patience PC, Kretzschmar A, Bichev D, Deist T, Hinke A, Breithaupt K, Dogan Y, Gebauer B, Schumacher G, Reichardt P (2011) Survival advantage for irinotecan versus best supportive care as second-line chemotherapy in gastric cancer-a randomised phase III study of the Arbeitsgemeinschaft Internistische Onkologie (AIO). Eur J Cancer 47: 2306-2314.

Wang W, Li YF, Sun XW, Chen YB, Li W, Xu DZ, Guan XX, Huang CY, Zhan YQ, Zhou ZW (2010) Prognosis of 980 patients with gastric cancer after surgical resection. Chin J Cancer 29: 923-930.

Wesolowski R, Lee C, Kim R (2009) Is there a role for second-line chemotherapy in advanced gastric cancer? Lancet Oncol 10: 903-912.

Wilke H, Muro K, van Cutsem E, Oh SC, Bodoky G, Shimada Y, Hironaka S, Sugimoto N, Lipatov O, Kim TY, Cunningham D, Rougier P, Komatsu Y, Ajani J, Emig M, Carlesi R, Ferry D, Chandrawansa K, Schwartz JD, Ohtsu A. GROUP, R. S. (2014) Ramucirumab plus paclitaxel versus placebo plus paclitaxel in patients with previously treated advanced gastric or gastro-oesophageal junction adenocarcinoma (RAINBOW): a doubleblind, randomised phase 3 trial. Lancet Oncol 15: 1224-1235.

This work is published under the standard license to publish agreement. After 12 months the work will become freely available and the license terms will switch to a Creative Commons AttributionNonCommercial-Share Alike 3.0 Unported License. 